\title{
The Development Model of American Rural Tourism and Its Enlightenment to China
}

\author{
Guangming Yang \\ College of management \\ Chongqing University of Technology \\ Chongqing, China 400054
}

\author{
Hong Ye \\ College of management \\ Chongqing University of Technology \\ Chongqing, China 400054 \\ Hao Zhang \\ College of management \\ Chongqing University of Technology \\ Chongqing, China 400054
}

\author{
Hang Yang \\ College of management \\ Chongqing University of Technology \\ Chongqing, China 400054 \\ Yanjun Shi \\ College of management \\ Chongqing University of Technology \\ Chongqing, China 400054
}

\begin{abstract}
As the process of urbanization accelerates in the world, more and more urban residents begin to search for villages where they can relax as well as appreciate the beautiful natural environment and its culture. Rural tourism becomes a hit. The rural tourism industry in the United States is a unique industry that has been gaining prominence since the foundation of the United States. This paper explores the resources that support modes of the development of American rural tourism by combing and comparing the characteristics of American rural tourism development. Finally, the paper summarizes the history and characteristics of American rural tourism development and summarizes the lessons that can be learned from the development of rural tourism in China.
\end{abstract}

Keywords-rural tourism; relying on resource; rural culture and creation; Internet of Things thinking

\section{INTRODUCTION}

As a form of tourists' return from urban areas to rural areas for tourism consumption and tourism experience activities, rural tourism is a phenomenon of tourists returning inevitably to a certain stage of tourism development. Rural tourism originated in the rural areas of France in the late 19th century and soon developed rapidly in the rural areas of developed countries in Europe and the United States. Its industrial development showed the characteristics of "high income and no pollution", which greatly promoted the economic development in rural areas. It maintains intact in terms of ecological environment in local communities and is considered as important means to promote agricultural

Funding Project: Ph.D. Program of Social Sciences Planning of Chongqing Municipality "research on the Coordinated Development Path of Moderate Population, Economic Growth and Ecological Carrying of the Three Gorges Reservoir Area", Approval No. 2015BS025. economic growth, increase incomes of rural residents and optimize agricultural industrial structure. After more than a century of development, these developed countries have achieved a high level of urbanization around the 1970s. The bustling urban environment prompted residents to have the idea of leading a rural life. Rural tourism has been vigorously promoted in Europe and the United States.

The vast territory of the United States and its wellmaintained rural culture has prompted it to become a country with more successful rural tourism development. According to the World Travel and Tourism Commission (WTTC), the U.S. tourism industry and its related industries generate about 3 trillion U.S. dollars in economic value annually, and this figure is still growing. Second, the huge demand for tourism and tourism has caused the skyrocketing employment posts. Direct and indirect employment created by the development of the tourism industry has been the head of various industries in recent years and the tourism industry has gradually become one of the career choices for young people in the United States [1]. The United States has a wide range of rural tourism. Both the western coast and the vast inland regions of the west have been deployed by the U.S. government as important destinations for rural tourism. Among them, many national parks, national public wetlands and various types of land and water areas have gained many social benefits and significant economic and ecological benefits. 


\section{RURAL TOURISM INTERNATIONAL STANDARDS AND CONNOTATION}

\section{A. The Country's International Standards}

American scholar Lenn summed up three points on the basis of their predecessors to divide the village: 1. Proper rural size and reasonable population 2. Land-use output 3. Changes in social class. The academic consensus on the countryside is that the countryside is the most important nonurban area, and generally has a lower population density and a smaller size of the town. Because different countries have different national conditions, there are many criteria for determining whether there are rural areas according to the population density. For example, a population of less than 1,000 in Australia can be called a village, a population of less than 1,000 in Canada and a population density of less than 400 people per square For the United States, only communities with a permanent resident population of less than 2500 are placed in the villages. Based on the latest U.S. census, the United States now has 2052 non-urban counties, accounting for $75 \%$ of the total land area, with a total population of $17 \%$, outstanding features to many people, rural tourism has a huge potential for development.

\section{B. The International Connotation of Rural Tourism}

For most city dwellers, their feelings and memories of rural tourism are no longer merely outward-looking representations, such as open fields and fresh air. The concept of village is not only based on the geographical features and social characteristics of its visualization, but also as a conceptual language frequently used in daily life of the people to make a distinction with urban life. Therefore, rural tourism can be defined as "rural experiential activities" that take place in all non-urban areas and include the following elements: 1 . Occur in rural areas 2. Functionally local-oriented 3. Rural-scale. 4. essentially traditional.

As the process of urbanization continues to accelerate, the pros and cons of cities are emerging. On the one hand, excellent infrastructure brings great convenience to people; on the other hand, the pressure of urban life increases and the indifference of interpersonal relations also highlights. This has prompted a mellow rural life to become an ideal destination for urbanites. Rural tourism is to seek in such an environment for the urban population to provide a relaxing and elegant lifestyle.

\section{The Origin and Background of the Development of American Rural Tourism}

Modern rural tourism originated in the United Kingdom in the middle and late 19th century. The first rural tourists did not enter the countryside with tourism as the primary goal. A large part of them went into rural life with the curiosity and mystery. Rural tourism entered the stage of popularization and development in Spain, which began in the 1960s. For the first time, rural tourism was integrated with domestic cultural and tourism resources, supplemented by farm management, and formed a rural tourism destination with folk customs [2]. The American rural tourism originated in the early 20th century and thrived at the end of the last century. Its motivation for development mainly included the following: transportation development, the establishment of a national park system, the stimulation of World War II and related policies.

The continuous construction and improvement of the railway network and the road network are the basic guarantees for the development of rural tourism. The rise and perfection of the first rural tourism destinations in the United States was mainly developed through the construction of a densely developed railroad. The improvement of the intercontinental road network made up for the short board that the railway network could not reach and provided the remote rural areas that the railway could not reach Access to conditions, located in the traffic lane on both sides of the portal community has become an important tourist destination. The local pillar industries also have a tendency to move closer to the tourism industry.

- The Role of American National Park System in Promoting. At the beginning of the 20th century, with the spread of environmental protection concept and the request of many environmentalists, the United States established a national park system. Various agencies involved in management systems such as forests and wetlands have been established in succession. Large quantities of high-quality wasteland have been protected. In the second half of the 20th century, public land tendencies tended to be recreated. The most important legal document is the Wilderness Act passed in 1964. Rural tourism researchers recognize this as a golden age for the development of American rural tourism.

- The Contribution of Infrastructure Construction in World War to American Rural Tourism. Due to the needs of wartime transportation and the great development of the domestic military industry, the U.S. infrastructure projects such as roads, hydropower and energy transportation have enjoyed a high degree of post-war development. As the war ended and people returned to normal life, rural tourism One of the reasons for the boom in the United States and Canada is that the equipment left behind by the war has become the hardware condition for rural tourism such as jeeps used for sightseeing and passenger rafting and outdoor rafting and so on. One of the most special cross-country skiing industries [3] has contributed to the emergence and growth of major US rural tourism projects and sports and leisure industries.

\section{THE CHARACTERISTICS OF AMERICAN RURAL TOURISM DEVELOPMENT}

\section{A. Planning Based on the Actual, Scientific Management Norms}

The U.S. government and its people attach great importance to the rational planning of rural tourism. The rationality of the rural tourism planning in the United States lies in that the U.S. government decentralized its power 
levels so that local governments can carry out scientific research according to law and scientifically and study the market preferences to guide residents to adjust their production and management directions and make full use of the local natural and human resources Tourism resources, produce a large number of tourists favorite travel products. The other reason is that the U.S. officials pay more attention to the scientific forecast in advance for the planning of tourist destinations within the jurisdiction, realize the realtime monitoring in the matter, promptly collect and handle the public's reaction to the scenic operation afterwards, govern the rural tourism destination in the form of full supervision and form a model for scientific development that runs through both decision-making and testing. The development of rural tourism in the United States is precisely due to the fact that it has been able to achieve sustained development with the realization of a win-win situation of social and economic benefits based on actual planning and monitoring throughout the entire project.

\section{B. The High Participation of Residents, Strong Sense of Ownership}

In terms of public scenic spot construction, the U.S. rural tourism administrations vigorously promote the PR marketing campaign so that the government can fully understand the relevant policies and measures for the development and promotion of rural tourism destinations (such as enhancing the brand influence of the region, expanding domestic demand and spending, Increase employment opportunities, and increase community welfare for residents, etc.). Through vigorous publicity among residents, an interest attraction and an impression of reputation are formed, and residents who are willing to take the initiative to participate in the operation and management of the scenic spots are taken initiatively. In terms of residents' autonomous construction, after World War II, life has become an increasingly sought after way of life for the urban middle class. Holiday choices are spent in rural bed and breakfasts in urban areas. Residents in different regions and different tourist resources flow into each other. People have multiple identities and are deeply embedded in the development and operation of rural tourism. Residents have a more thorough understanding of tourism policies, tourism formats and government behaviors, and even a stronger identity of themselves.

\section{Tourists High Environmental Awareness, the Formation of Development Community}

As a country that has a very high degree of protection on its own ecological environment in the world, the concept of a low-carbon economy and green recycling has long been popular in the United States. American rural tourism enthusiasts pay great attention to the protection of rural environment in the process of traveling and sightseeing. The United States does not allow tourists to carry non-degradable packaging materials into the area, usually bring their own environmental garbage bags to collect their own garbage, the scenic spot will also attach great importance to the rapid recycling of production and household waste. The development of rural tourism destinations in the United
States is mature, and the tourism ecology has always maintained a high level. This is due to the rational planning based on the entire field of the US rural tourism administration. This example warns our countries' rural tourism planning department to guide the tourism planning based on the pattern of "global tourism". It scientifically improves the hardware and software environment of rural tourism destinations on the basis of global considerations, gross and precise planning and overall planning, and advocates the promotion of rural people, financial and material resources. Wisdom and other resources can be used to create a livable natural environment and elegant culture. Besides, the improving incentives and proper punishments can reduce the damage that poor behaviors of tourists may cause when appreciating tourist sights.

\section{Development of Independence, Emphasis on Sustainable Development}

Most of the rural tourism sites are located in areas with good ecological environment, abundant natural resources and less human interference. These areas often have the dual characteristics of beautiful environment and ecological fragility. In the process of tourism planning, American rural tourists inevitably have to deal with the problems between economic development and ecological protection. The development of rural tourism will drive the development of the local economy, but it will inevitably bring negative impacts on the environment, especially hot tourist attractions. Excessive population will exert tremendous pressure on the infrastructure and environment. The state officials in the United States popular are aware of this problem, and have introduced measures to settle the matter. For example, Tennessee will base on real-time detection of the number of scenic spots, limiting the flow of people in some scenic spots, incentives and rewards for the introduction of bad behavior [4].

\section{E. High Economic Efficiency, Strong Combination of Agricultural Brigade}

Compared with the tourism industry's input-output ratio of the major tourist countries in the world, the benefits of US rural tourism undoubtedly belong to the highest echelon, which is mainly from product quality control, industrial chain integration, strong marketing advantage to analyze. American rural tourism product control the entire field of its industry, including the quality control of rural agricultural products, rural tourism projects and line quality control, rural cultural and creative product quality control, quality control and other aspects of service. In this case, the United States not only has a strict rural tourism products Screening criteria, besides, it is with a strict high standard of protection, lays the cornerstone of its high economic efficiency of the product; the United States rural tourism industry chain is also the integration of the entire industry, service, finance and tourism are carried out with the local Depth integration, accurate convergence between different levels of industry, all of which are integrated with each other as raw materials and finished product and greatly ensure the effective and rational use of resources. The business model in the United States is one of the important ways to promote its economic 
efficiency and publicity. In combination with traditional paper and television media, it has vigorously launched a global campaign and actively has absorbed the latest marketing tools. For example, community marketing, online marketing, real experience, VR simulation and a full range of three-dimensional marketing are designed to provide consumers with authentic rural experience.

\section{F. Grasp the Core Competitiveness, Strong Momentum of Development}

The independence of the development of rural tourism in the United States means that in the process of its industrial development, the core industrial departments are not entrusted with the rise and fall of the development of an external industry. Instead, they operate independently and are responsible for their own profits and losses. The root of independent development comes from the great autonomy given by the federal government to the tourism industry. The United States Congress established the U.S. National Tourism and Tourism Administration, and the following year witnessed the establishment of a national rural tourism fund. The jurisdiction of American rural tourism is gradually transferred from the federal government to the state governments, and the township government also has certain rights to make decisions and suggestions. Such decentralization will enable tourism decision-makers to be closer to the real reality and to guide the development of the local tourism industry more scientifically and rationally.

\section{THE ENLIGHTENMENT AND EXPERIENCE OF AMERICAN RURAL TOURISM DEVELOPMENT}

\section{A. Strengthen the Awareness of Resources, Highlighting the} Harmony between Human and Natural Resources

The key to the development of rural tourism lies in whether tourism resources are found, including various types of natural or human resources. Rural tourism destinations are based on the local natural resources, and then appropriately supplemented by other types of resources [5]. The resourcebased mode that widely researched is listed as follow:

1) Base on natural resources: The rural tourism in the early time mostly relies on the natural resources within its jurisdiction, such as fishing in the central and western regions, hillside skiing in the western mountainous areas, and camping in the western beaches. Most of the portal communities rely on the local unique natural resources to complete the initial accumulation of industrial base and provide protection for the subsequent form of tourism development and product upgrading.

2) Based on historical and cultural resources: Cultural heritage tourism is a new form of tourism that has developed as people focus on improving the quality of cultural life. The western United States is now the best known for its denim culture and ruin culture. The development of rural tourism in the United States is also borrowed from these two highly-colored cultures, such as abandoned mills, glass factories, coal mines, auto repair shops and cowboys Bar and cowboy fighting venue. They have become an important symbol of American rural culture.

3) To organize festival activities as the basis: Festival activities can be used as a theme of rally in the form of tourists will be attracted to the destination in order to achieve the completion of tourism consumption, promote the festival culture communication process. Anniversary of Civil War in many towns and communities in the United States and Goa in California is known as the capital of the world garlic and Seymour in Wisconsin is famous for its hamburger rally.

4) The original ecological agriculture resources and modern large-scale agricultural supermarket based on the combination: Under the premise of ensuring the quality of agricultural resources development, many large-scale agricultural production areas in the United States will deploy large-scale agricultural supermarkets with a full range of products and a wide range of radiation in their fringe areas. These supermarkets, with their products being inexpensive and with advanced management and operation experience, is known as sources and other characteristics. Combination of high-quality agricultural resources and large-scale agricultural supermarkets, commonly known as the "shop before the factory" model, this model is not only commercial innovation, but also the integration of tourism landscape and experience design.

5) To focus on creating "user experience" that is based real experience and cultural creation that is based on the combination: With the development of logic and thinking concept of creative style industry, people integrate the characteristics of tourism agriculture, integrate science and technology, urban planning and humanities elements effectively into agricultural production, dig out agricultural functions and integrate agricultural resources on the basis of paying attention to users' experience and thus transforming traditional agriculture into a modern agriculture integrating production, living and ecology. This practice has extended the industrial chain and increased the chances of peasants in creating wealth and increasing employment. The typical mode of real experience in rural tourism in the United States is family farms, rural bed and breakfasts and private agricultural museums. All of these modes have in common with each other through a series of artistic and design methods to create ideal scenes in people's hearts and create an ecology Healthy farm environment to attract a large number of farmers have a special feeling of tourists to experience.

\section{B. The First Government Visit, Tourism Legislation Escort, the Policy of Financial Support}

The development of rural tourism before and the consolidation as well as maintenance in the latter stage mainly rely on the macro-control of local government. All subordinate departments should clearly define their own responsibilities, give full play to their own auxiliary role, and jointly conduct joint actions. First of all, the competent 
agricultural departments and tourism departments in the area jointly set up a joint agency for rural tourism management, formulated development goals and planning ideas that are in line with actual conditions, established an open and transparent operating mechanism, formulated policy-making and management rights and plans for the long-term development of local tourism Coordinate and deal with the construction authority, after-the-fact supervision mechanism and marketing work. Second, it is necessary to give play to the supervisory role of the government and social organizations, coordinate the resolution of the contradictions between the economy and the community in the development of scenic spots, and provide supporting systems in various fields such as training, finance, technology and information.

Local policy support and foreign capital investment also play a fundamental supporting role in the development of rural tourism. As an effective means of promoting rural development after the tourism industry enters rural areas, the rural tourism economic model is very important. The government not only needs to increase policy support and capital investment for rural tourism under the precondition of ensuring normal agricultural production, but also provides government support such as land circulation, financial subsidies and technical consultation in light of the needs of farmers and the rural status quo, all of which is meant to provide official service in terms of capital investment and excellent infrastructure construction conditions etc. [6].

To promote rural tourism economy is to establish rural tourism mechanism and improve relevant laws and regulations. The Chinese government must seize the opportunity of big tourism development and put the normative and scientific development tourism on the national agenda, such as "Rural Tourism Development Plan" and "Rural Tourism Promotion Plan". The government and administrative departments should implement the Regulations for the Planning and Construction of Rural Tourist Destinations, Regulations for the Administration of the Employment of Rural Tour Operators, Regulations for the Administration of Rural Tourism Quality Complaints and Responsibilities and Accidents, in order to ensure the constant development of rural tourism.

\section{Tap the Cultural Connotation of Rural Areas, and Strengthen the Integration of Cultural and Creative Experience}

In the initial development of the rural tourism-related projects in the United States and the excavation of its connotation, the rural tourism destinations satisfy tourist psychology such as "hometown plots" and "return to nature" by interpreting the original rural culture [7]. Long history of rural areas and rural culture with unique local characteristics are planned to attract tourists' attention and utilize the tourism resources. Fully exploitation of the unique cultural connotations of different historical periods, including the traditional rural history, original farming practices, simple rural culture and green pastoral culture, is the key to maintaining a sustained attractive and self-renewal of rural tourism. The connotation of rural tourism culture can be learned from the context, context, connections and sentiments of the village. In the architectural design and alternative use both need to refer to the classic antiquity, but also with the trend of modern fashion, from the rural history to seek inspiration, and strive to stimulate tourists from the senses of cultural resonance; in the restaurant, you can implement the use of rustic local kitchen stove. The production process of the native materials can offer visitors a rustic diet experience. And the exposure to the rural tourist spots, combined with the above aspects, such as farming experience, pastoral experience, ranch festivals, agricultural DIY, can attract tourists broadly.

Rural tourism product is the material carrier of rural tourism development. Its product innovation can start with product form innovation, product content innovation and product function innovation. Formal innovation includes external packaging and innovation of internal structure. Through the means of packaging rural cultural environment and innovative packaging of physical products, the pursuit of refreshing experience for tourists in the design sense is organized. Correspondingly, the planning and organizing of tourists to participate in the naming of tourist destinations, Adoption of animals and plants activities can not only give travelers the primitive simplicity of labor experience, but also avoid the design of tourist souvenir effect stereotyped dilemma. The innovation of rural tourism product content is entirely based on the large and rich connotation of rural tourism resources. With reference to the changes of consumer tastes in the market and the development of characteristic rural tourism products according to local conditions, Successful cases at home and abroad are abound, such as the Castle Hotel in Spain, the Songcheng area in Hangzhou, China, and the wife in Japan. The functional innovation of rural tourism products is based on the diversification of tourists' consumption demand, and horizontally extends the social functions, learning functions and learning functions of tourism products. For example, it provides cultural and creative agricultural experience, independent processing of agricultural and sideline products, souvenir customization. Moreover, other activities can not only enhance the tourists experience in the rural tourism, but also extend the tourist stay and spending time.

\section{Implement a Diversified Marketing Strategy, into the Internet of Things Thinking, to Achieve Sustainable Use of Resources}

The marketing and management of rural tourism destinations should abandon the original extensive mode and adopt diversified composite marketing mode so as to cultivate the market fully and deeply [8]. First, it is necessary to make full use of the traditional paper or radio and television marketing model to enhance the market awareness of rural tourism destinations, that is, it is needed to carry out tourism promotion on the traditional marketing media such as TV broadcasts, newspapers and magazines, professional wall advertisements and so on to enhance the market visibility of tourist destinations. The second is to strengthen the cooperation and exchange with local tourism operators and competent agencies by taking advantage of the explosive 
trend of modern Internet information and innovative network marketing tools by using the emerging means such as microblog marketing, mobile phone marketing and film and television marketing that young people now like to take full advantage of. The main advantages of the agency are to create a more influential rural tourism site for the intention of tourists and potential travelers to provide tourism resources query, recommended routes, product introduction and related exchanges and interactive after-sales service. The third is to promote the development of thematic festival marketing. By exploring the cultural connotation of rural natural resources, cultural resources and folk custom products in various directions, the campaign will create momentum for festivals and display the brand image of rural tourism destinations.

Internet of Things thinking is based on the social organization structure of thinking. The Internet of Things regards all kinds of people, things, technologies and funds as part of the real world. Through the rational allocation of various types of resources, the goal of improving resource utilization efficiency and raising input-output ratio is achieved. The development of rural tourism should make full use of the advantages of the Internet of Things to integrate resources such as intelligence, capital, land and products in the region so that the network and resources can interact with each other and form a physical Internet in the tourism industry. The use of Internet of Things thinking will greatly improve the current distribution of tourism resources and match the distribution of tourism information through the resource providers and consumers together to achieve the balance of the uses of all types of resources.

\section{CONCLUSION}

Based on the research on the background, causes, process and characteristics of rural tourism in developed countries, this paper mainly studies the whole process of the development of American rural tourism and summarizes its main positive factors: First, laying a legal basis for the establishment of rural tourism laws based on a national level . Second, industrial support policies promulgated at the national level have been used to boost industrial implementation. Third, we must fully introduce external intellectual resources and make efforts to promote the innovation of township travel operations and consumption forms. Fourth, fully mobilize the community forces to protect their own self-interests is highly achievable.

Rural tourism in China goes hand in hand with the profound changes as the urbanization process deepens. By analyzing the advantages and disadvantages of the development of American rural tourism industry, the article briefly introduces the overall train of thought of rural tourism development and hopes to provide experience and reference for the development of vast rural tourism destinations in China.

\section{REFERENCES}

[1] The World Travel \& Tourism Council.Travel \& Tourism Economic Impact 2014 Americas [R].London:Oxford University Press,2014:3-5
[2] Yang Ran Ran. Combined with foreign experience on the development of China's rural tourism strategy [J]. Business Economics, 2016 (5): 75-76.

[3] Ding Jie.Study on the Development and Enlightenment of American Rural Tourism Based on the Background of Urbanization [J] .China Famous City, 2017 (2): 33-37.

[4] Jinlian, Cui Yue, Huang Xiankai.Enlightenment of American Rural Tourism Development on Beijing [J]. Journal of China Agricultural University, 2015, 20 (5): 289-296.

[5] Huang Haihui.Discussion on the development model of rural tourism in developed countries and regions [J]. Heilongjiang Foreign Trade and Economic Cooperation, 2011 (6): 112- 114.

[6] Deng Jinyang, Zhang Yaoqi. American Rural Tourism Development [J]. Forestry Economics, 2007, 27 (4): 335-340.

[7] Ling Lijun.Study on the Development of American Rural Tourism [J]. World Agriculture, 2015 (10): 60-63.

[8] DAI Bin, ZHOU Xiao-song, LIANG Zhuang-ping.Comparative Study on the Development Models of Rural Tourism in China and Abroad [J]. Journal of Jiangxi Science \& Technology Normal University, 2006 (1): 16-23. 